\title{
A case of the Zollinger-Ellison syndrome associated with hyperplasia of salivary and Brunner's glands
}

\author{
B. S. JONES, J. J. O'HAGAN, D. N. PHEAR, AND E. SHEVille \\ From the Queen Elizabeth II Hospital, Welwyn Garden City
}

SUMMARY A case is reported showing enlargement of the salivary gland with hypersecretion and Brunner's gland hyperplasia in the Zollinger-Ellison syndrome. Gastric hypersecretion and diarrhoea were prominent, but there was no peptic ulceration.

Zollinger and Ellison (1955) described the syndrome of recurrent peptic ulceration, gastric hypersecretion, and associated pancreatic isletcell tumour. Since then over 600 cases of the syndrome have been described, and over 20 of the subgroup with watery diarrhoea and electrolyte depletion as the predominant feature (Priest and Alexander, 1957). These patients with diarrhoea may show gastric hypersecretion, but some have a normal or low gastric output (Espiner and Beaven, 1962).

The present case is reported to record the association of the Zollinger-Ellison syndrome with hyperplasia of the salivary and Brunner's glands.

\section{Case Report}

An Englishman aged 41 years was admitted on 10 September 1964. He gave a 10-month history of persistent watery diarrhoea, having two to four motions daily with a total volume of about 2 litres. For three months he had noticed painless, symmetrical enlargement of the parotid glands and, to a lesser extent, of the submandibular glands. There was persistent excessive salivation, continuing day and night and not particularly increased by meals. The amount of salivary secretion required frequent expectoration into paper handkerchiefs by day, and left a large pool of Received for publication 9 March 1970. saliva on his pillow and pyjama coat at night. He had complained for three months of epigastric pain and heartburn, with vomiting of about 500 $\mathrm{ml}$ of acid fluid each morning. The appetite had been poor for a year, with loss of 3 stone in weight.

Examination showed him to be thin, with the firm, smooth enlargement of parotid and submandibular glands (Fig. 1). The liver was enlarged five fingerbreadths, and was hard. Investigations showed haemoglobin levels varying between 112 and $125 \%$ from dehydration. The initial serum potassium level was $3.1 \mathrm{~m}$-equiv/litre. The tests for faecal fat excretion and for xylose tolerance were normal. A barium meal showed thickening of mucosal folds in the stomach; the mucosa of the duodenal cap and loop showed the cobblestone appearance of Brunner's gland hypertrophy (Fig. 2). Overnight aspiration of gastric juice for 12 hours yielded $1,500 \mathrm{ml}$ with $115 \mathrm{~m}$ equiv $\mathrm{HCl}$, and on another occasion $1,250 \mathrm{ml}$ with 170 m-equiv $\mathrm{HCl}$. Diarrhoea improved temporarily during these aspirations.

The patient failed to respond to antispasmodics and alkali, and, on 30 October 1964, a laparotomy was performed by Mr G. F. Cassie. A hard tumour was found in the tail of the pancreas, with many liver metastases; histology of a liver nodule confirmed the diagnosis of non- $\beta$ islet cell carcinoma (Dr J. I. Pugh). The postoperative course was stormy with pulmonary atelectasis, and an exacerbation of diarrhoea with dehydration and electrolyte imbalance. He showed remark- 


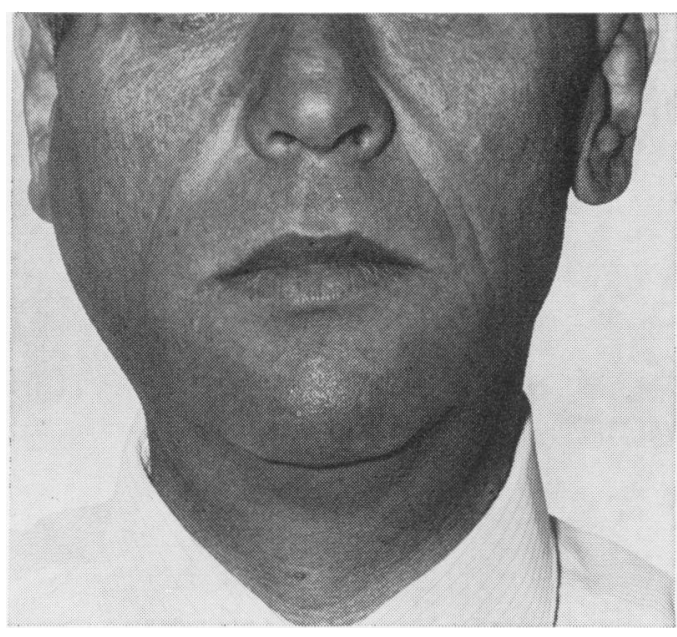

Fig. 1 Enlargement of the right parotid and submandibular glands. The left parotid gland is reduced in size after radiotherapy.

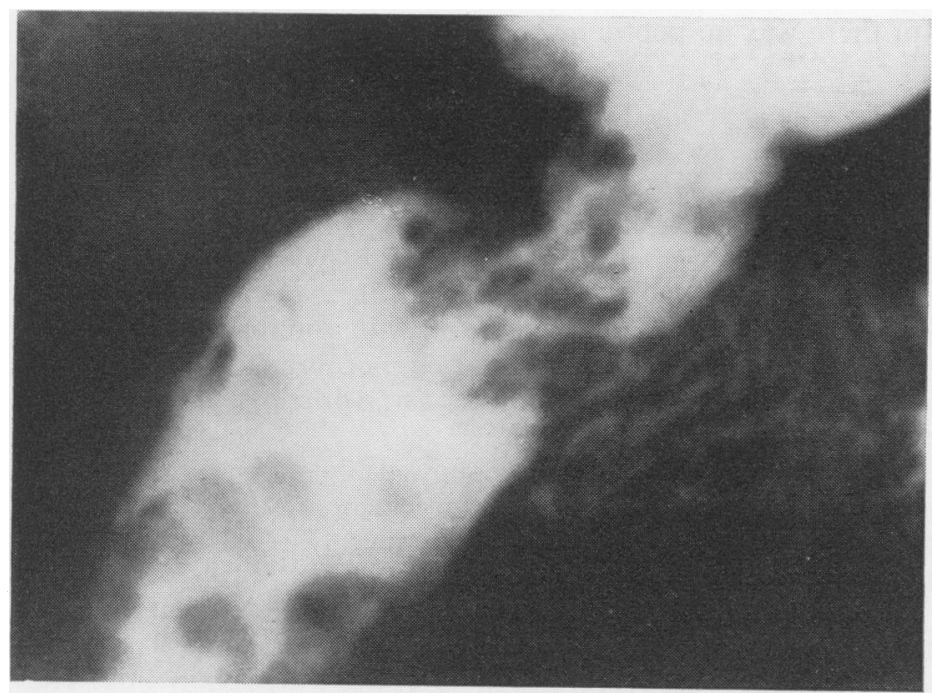

Fig. 2 Cobblestone appearance of the duodenum during barium meal examination.

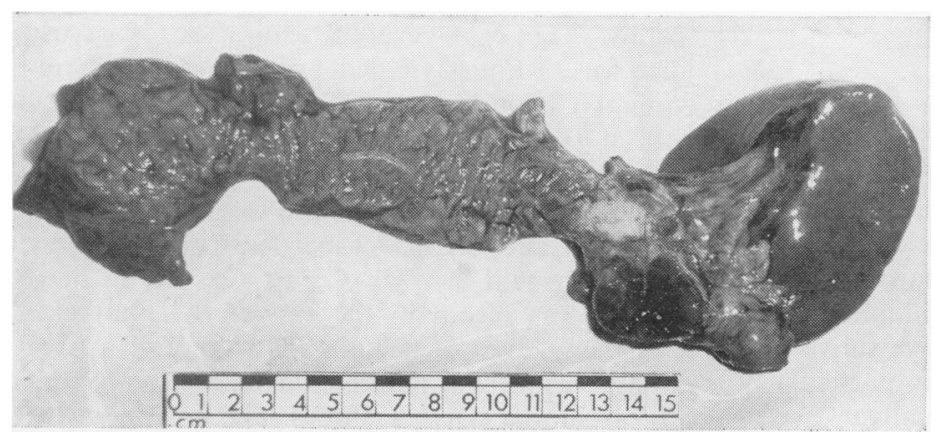

Fig. 3 Tumour mass in the tail of the pancreas, adjacent to the spleen. able improvement with prednisone, reported to be valuable for the control of intractable diarrhoea in the Zollinger-Ellison syndrome (Smith, 1965), and, thereafter, diarrhoea was treated with prednisone and antispasmodics. In February 1965 he developed diabetes, requiring insulin. In April 1965 he received radiotherapy to the left parotid gland (Dr S. Dische), with good control of the excessive salivation. In July 1965 the 12hour nocturnal gastric aspirate measured $800 \mathrm{ml}$ containing $40 \mathrm{~m}$-equiv $\mathrm{HCl}$. This reduction of acid secretion was associated with a steady decrease in gastric symptoms. He returned to parttime work after the laparotomy, usually passing two large motions daily, with several exacerbations of diarrhoea and vomiting requiring intravenous fluid and electrolyte replacement. His final exacerbation was in September 1966, when he did not respond to electrolyte correction and died, just three years after the onset of symptoms.

\section{NECROPSY EXAMINATION}

The examination showed a carcinoma in the tail of the pancreas, measuring $4 \mathrm{~cm}$ diameter (Fig. 3). There were extensive secondary deposits in the liver. The salivary gland enlargement was confirmed, and there was gross hyperplasia of Brunner's glands (Fig. 4). Tumour deposits from the liver did not contain gastrin, perhaps because of delay in obtaining the tissue.

\section{Discussion}

This case report describes for the first time the association of enlargement with hypersecretion of the salivary glands and hyperplasia of Brunner's glands with the Zollinger-Ellison syndrome. Hyperplasia of the gastric mucosa is a constant finding, and sometimes produces 'tumour-like' masses (Ottenjann, Gall, and Elster, 1967) but similar mucosal hyperplasia outside the stomach has not been recognized. Stimulation of salivary and duodenal glands in our patient could result from the secretion by the tumour of a peptide hormone other than gastrin (Sircus, 1969).

Brunner's glands are coiled tubules lying below the muscularis mucosae of the duodenum and producing a mucoid, slightly alkaline secretion, containing a small amount of pepsin. Secretion can be provoked by vagal stimulation, or by a hormone extracted from the pyloro-duodenal mucosa which is not secretin (Cooke and Grossman, 1966). The mucus secretion of Brunner's glands is probably important in protecting the duodenum from gastric acid and pepsin, and the increased secretion in our patient may have contributed to prevent peptic ulceration. Hyperplasia of the glands is recognized radiologically, or at operation or necropsy, by a cobblestone 


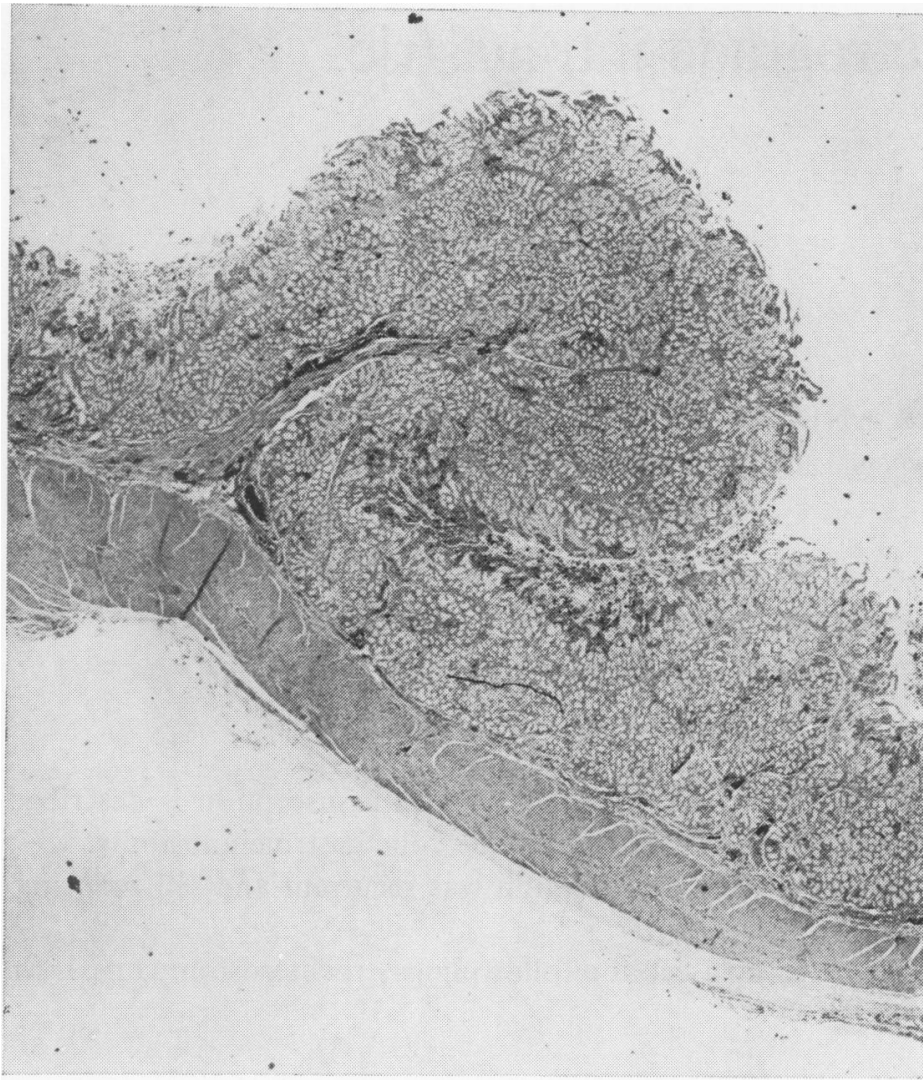

Fig. 4 Duodenal wall, showing grossly thickened mucosa from hyperplasia of Brunner's gland.

appearance of the duodenal mucosa. The appearances may be difficult to distinguish from thickened mucosal folds in the duodenum in association with high gastric acidity (Rhodes, Lawrie, and Evans, 1968). Brunner's gland enlargement is occasionally associated with bleeding, or with intestinal obstruction by intussusception of a polypoid mass; more often, indefinite dyspepsia occurs or there are no symptoms (Kaplan, Dyson, and Fitts, 1968). The gastric acidity in these patients is often high, but may be normal or low. For this reason, and because Brunner's gland hyperplasia has not before been reported in the Zollinger-Ellison syndrome, the hyperplasia is not a simple response to excess duodenal acidity.

The cause of the diarrhoea in the ZollingerEllison syndrome remains in doubt. Gastrin itself may be responsible for the diarrhoea, for it is known to increase motility in stomach, small intestine, and colon (Gregory and Tracy, 1964).
Removal of gastric juice by nasogastric suction may produce temporary improvement, as in our patient. This has suggested that the diarrhoea results from inactivation of pancreatic enzymes, especially lipase, by the acid duodenal contents. Diarrhoea has been controlled, also, by reduction of hyperacidity with atropine (Vogel, Weinstein, Hersovic, and Spiro, 1967). The excessive acid secretion may be responsible for abnormalities in the jejunal mucosa which have been reported in the Zollinger-Ellison syndrome (Parrish and Rawlins, 1965), and these mucosal changes may contribute to diarrhoea. A few of these patients show diarrhoea but no gastric hypersecretion, and diarrhoea persisted in our patient after gastric acid secretion had returned to normal. Such a situation could result from the production by the tumour of secretin, or a hormone stimulating secretin production, with decreased production of gastrin (Sircus, 1969).

The pancreatic tumour in our patient was not extensive enough to produce diabetes and there was no family history of diabetes. Other factors possibly responsible for impaired glucose tolerance were the corticosteroid treatment and the extensive liver metastases.

We are very grateful to Professor R. A. Gregory for his advice, and for assaying the tumour tissue for gastrin.

References

Cooke, A. R., and Grossman, M. I. (1966). Studies on the secretion and motility of Brunner's gland pouches. Gastroenterology, 51, 506-514.

Espiner, E. A., and Beaven, D. W. (1962). Non-specific islet-cell tumour of the pancreas with diarrhoea. Quart. J. Med., $31,447-471$.

Gregory, R. A., and Tracy, H. J. (1964). A note on the nature of the gastrin-like stimulant present in Zollinger-Ellison tumours. Gut, 5, 115-117.

Kaplan, E. L., Dyson, W. L., and Fitts, W. T. (1968). Hyperplasia of Brunner's glands of the duodenum. Surg. Gynec. Obstet., 126, 371-375.

Ottenjann, R., Gall, F., and Elster, K. (1967). Tumor-förmige hyperplasie der magenschleimhaut bei Zollinger-Ellison Syndrom. Dtsch. med. Wschr., 92, 1538-1546.

Parrish, J. A., and Rawlins, D. C. (1965). Intestinal mucosa in the Zollinger-Ellison syndrome. Gut, 6, 286-289.

Priest, W. M., and Alexander, M. K. (1957). Islet-cell tumour of the pancreas with peptic ulceration, diarrhoea, and hypokalaemia. Lancet, 2, 1145-1147.

Rhodes, J., Lawrie, J. H., and Evans, K. T. (1968). Coarse duodenal folds in patients with peptic ulcer. Gut, 9, 609-611.

Sircus, W. (1969). Peptide-secreting tumours with special reference to the pancreas. Gut, 10, 506-515.

Smith, R. (1965). The Zollinger-Ellison syndrome. Ann. roy. Coll. Surg. Engl., 37, 160-165.

Vogel, R. M., Weinstein, L. D., Herskovic, T., and Spiro, H.M. (1967). Mechanisms of steatorrhoea in the ZollingerEllison syndrome. Ann. intern. Med., 67, 816-822.

Zollinger, R. M., and Ellison, E. H. (1955). Primary peptic ulcerations of jejunum associated with islet cell tumours of the pancreas. Ann. Surg., 142, 709-728. 